\title{
Does Universal Bypass before Carotid Artery Occlusion Obviate the Need for Balloon Test Occlusion: Personal Experience with Extracranial-Intracranial Bypass in 23 Patients
}

Girish Menon, Sudha Menon', Ajay Hegde

Departments of Neurosurgery and ${ }^{1}$ Ophthalmology, Kasturba Medical College, Manipal, Karnataka, India
Aim: Carotid artery ligation carries a potential risk of ischemic complications even in patients with good collaterals and adequate cross-circulation. Preoperative assessment through balloon test occlusion (BTO) is technically challenging and not feasible in all patients. We analyze our experience with universal bypass without performing detailed cerebrovascular reserve (CVR) studies in 23 patients before carotid artery ligation. Patients and Methods: This was a retrospective analysis of the case records of 23 patients who underwent cervical carotid artery ligation for various indications since January 2009. Results: The study included 21 patients with cavernous carotid aneurysms, one patient with a large fusiform petrous carotid aneurysm, and one patient with recurrent glomus jugulare encasing the cervical internal carotid artery. The initial 12 patients underwent preoperative BTO with hypotensive challenge. All patients underwent a bypass procedure followed by carotid artery ligation irrespective of the BTO findings. Patients who successfully completed a BTO underwent a low-flow superficial temporal artery to middle cerebral artery bypass. A high-flow extracranial-intracranial bypass using a saphenous vein graft from external carotid artery to middle cerebral artery was done in all patients who either failed the BTO or did not undergo BTO. We had two operative mortalities and one poor outcome. All the other patients had a good recovery with a Glasgow outcome score of 5 at the last follow-up. Graft patency rates were $81.1 \%$ in both the low-flow and high-flow groups. Conclusion: Universal high-flow bypass is safe, effective, and should be preferred in all patients before carotid artery ligation. It obviates the need for detailed CVR assessment, especially in centers with limited resources.

KEYWORDS: Aneurysms, bypass surgery, clipping, coiling, revascularization

\section{INTRODUCTION}

$\mathrm{O}$ cclusion of the proximal carotid artery is part of the management strategy for few complex carotid aneurysms and some extensive skull base tumors. ${ }^{[1-6]}$ Carotid artery ligation carries a potential risk of ischemic complications which can be prevented by combining it with an extracranial-intracranial (EC-IC) bypass procedure. ${ }^{[7,8]}$ Not all patients, however, require a bypass procedure and those with good collaterals and cross-circulation can tolerate carotid occlusion well. Selection of patients warranting bypass is done through tests for cerebrovascular reserve (CVR), of

\begin{tabular}{|l|l|}
\hline \multicolumn{2}{|c|}{ Access this article online } \\
\hline Quick Response Code: & Website: \\
\hline
\end{tabular}

which balloon occlusion test is the one most commonly used. ${ }^{[9,10]}$ Recommendations suggest direct occlusion with or without an augmentative low-flow bypass (superficial temporal to middle cerebral [STMC]) for patients with good reserve and a high-flow bypass (EC-IC saphenous/radial artery) for those without adequate

Address for correspondence: Dr. Girish Menon, Department of Neurosurgery, Kasturba Medical College, Manipal - 576 104, Karnataka, India. E-mail: neuron1967@gmail.com

This is an open access journal, and articles are distributed under the terms of the Creative Commons Attribution-NonCommercial-ShareAlike 4.0 License, which allows others to remix, tweak, and build upon the work non-commercially, as long as appropriate credit is given and the new creations are licensed under the identical terms.

For reprints contact: reprints@medknow.com

How to cite this article: Menon G, Menon S, Hegde A. Does universal bypass before carotid artery occlusion obviate the need for balloon test occlusion: Personal experience with extracranial-intracranial bypass in 23 patients. J Neurosci Rural Pract 2019;10:194-200. 
Table 1: Clinical summary of the twenty three patients in the current series

\begin{tabular}{|c|c|c|c|c|c|c|c|}
\hline Age & Sex & Symptoms & Clinical Deficits & BTO & Procedure & Outcome & Graft Status \\
\hline 58 & $\mathrm{~F}$ & Periorbital pain, diplopia & Lateral rectus, partial $3^{\text {rd }}$ nerve palsy & Passed & STMC & Good & Thrombosed \\
\hline 46 & M & Diplopia & Lateral rectus palsy & Passed & STMC & Good & Patent \\
\hline 48 & $\mathrm{~F}$ & Diplopia & Lateral rectus palsy & Passed & STMC & Good & Patent \\
\hline 52 & $\mathrm{M}$ & Diplopia, Headache & Partial $3^{\text {rd }}$ Nerve palsy & Passed & STMC & Good & Patent \\
\hline 45 & $\mathrm{~F}$ & Headache, ptosis, diplopia & Opthalmoplegia & Passed & STMC & Good & Patent \\
\hline 43 & $\mathrm{~F}$ & Ptosis, diplopia, headache & Total opthalmoplegia & Passed & STMC & Dead & Patent \\
\hline 24 & $\mathrm{~F}$ & Headache, diplopia, ptosis & Partial $3^{\text {rd }}$ Nerve palsy & Passed & STMC & Good & Thrombosed \\
\hline 64 & $\mathrm{~F}$ & Periorbital pain, diplopia & Lateral rectus palsy & Failed & High flow & Good & Patent \\
\hline 60 & $\mathrm{~F}$ & Headache, Diplopia & Lateral rectus palsy & Passed & STMC & Good & Patent \\
\hline 50 & $\mathrm{~F}$ & Headache, Diplopia & Partial $3^{\text {rd }}$ Nerve palsy & Passed & STMC & Good & Patent \\
\hline 21 & M & Swelling in the left aside of neck & No deficits & Passed & STMC & Good & Patent \\
\hline 30 & M & Diplopia, facial pain & Lateral rectus palsy & Passed & STMC & Good & Patent \\
\hline 48 & $\mathrm{~F}$ & Diplopia & Lateral rectus palsy & Failed & High flow & Good & Patent \\
\hline 55 & $\mathrm{~F}$ & Diplopia & $3^{\text {rd }}$ Nerve Paresis & Passed & STMC & Good & Patent \\
\hline 65 & $\mathrm{~F}$ & Ptosis, diplopia & $3^{\text {rd }}$ Nerve Palsy & Not done & High flow & Vegetative & Patent \\
\hline 30 & M & Diplopia & Lateral rectus palsy & Not done & High flow & Good & Patent \\
\hline 43 & M & Ptosis, diplopia & Complete Opthalmoplegia & Not done & High flow & Good & Patent \\
\hline 60 & $\mathrm{~F}$ & Headache, vomiting, ptosis & Complete Opthalmoplegia & Not done & High flow & Good & Patent \\
\hline 19 & M & Epistasis, Blindness & $2^{\text {nd }}$ Nerve Palsy & Not done & High flow & Good & Patent \\
\hline 23 & M & Headache, altered sensorium & Nil & Not done & High flow & Dead & Thrombosed \\
\hline 55 & $\mathrm{~F}$ & Headache, vomiting, diplopia, ptosis & Partial $3^{\text {rd }}$ Nerve palsy & Not done & High flow & Good & Patent \\
\hline 37 & M & Headache , hearing loss & $7^{\text {th }}, 8^{\text {th }}, 9^{\text {th }}, 10,11,12^{\text {th }}$ Palsy & Not done & High flow & Good & Patent \\
\hline 60 & $\mathrm{~F}$ & Ptosis & Lateral rectus palsy & Not done & High Flow & Good & Patent \\
\hline
\end{tabular}

reserve. ${ }^{[1]}$ The tests for CVR are technically challenging, require expertise in interpretation, are not real time, and are not feasible in all patients. Moreover, patients are known to develop ischemic complications in spite of having adequate reserve as defined by these tests. ${ }^{[12]}$ Selection of patients and the decision on the appropriate surgery, thus, poses considerable dilemma. One practical solution is to perform a bypass for all patients irrespective of their CVR status (universal bypass). The authors describe their experience with universal bypass for 23 patients, 11 of whom underwent surgery without detailed preoperative assessment. The authors had earlier published their experience with 12 patients who had undergone BTO and augmentative STMC/high-flow bypass depending on the BTO tolerance. ${ }^{[13]}$ This article highlights a shift toward universal high-flow bypass in all such cases obviating the need for detailed CVR assessment.

\section{Patients and Methods}

Since January 2009, the first author performed 23 cases of EC-IC bypass revascularization before parent artery (internal carotid artery [ICA]) ligation. The study included 14 female and 9 male patients with ages ranging from 19 to 67 years (mean 45.22 years). Follow-up periods ranged from 6 months to 10 years (mean 26 months). The study group included twenty patients with large/giant cavernous carotid aneurysms (CCAs), one patient with a traumatic pseudoaneurysm, and one large fusiform cervical carotid aneurysm reaching the skull base. In one patient, a high-flow bypass was performed before radical resection of a recurrent glomus jugulare encasing the cervical ICA. These aneurysms were considered unsuitable for either surgical clipping due to various reasons such as cavernous sinus location, wide neck, fusi-saccular configuration, and giant size. Table 1 presents the summary demographic data of the 23 patients. All but one of the patients with cavernous aneurysms presented with features of cranial nerve paresis, with $3^{\text {rd }}$ nerve and $6^{\text {th }}$ nerve being most commonly affected [Table 1]. One patient presented with profuse epistaxis from a traumatic CCA following a head injury sustained 2 weeks prior [Figure 1], one patient presented with a high cervical mass, and the patient with glomus jugulare [Figure 2] presented with multiple cranial nerve palsies.

\section{Selection of operative procedure}

All patients underwent magnetic resonance imaging, computed tomographic (CT) scanning of the brain, and CT angiography (CTA) followed by digital subtraction cerebral angiography (DSA) with cross-compression studies. In the initial period, all patients (12 patients) having good cross-circulation through anterior communicating artery or posterior communicating artery were subjected to BTO with hypotensive challenge. 


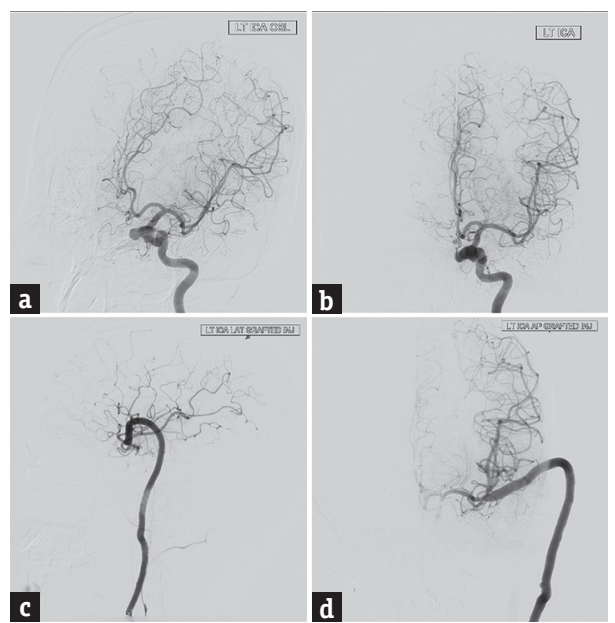

Figure 1: ( $a$ and b) Digital subtraction carotid angiogram a pseudoaneurysm in the cavernous carotid artery on the left side, (c and d) digital subtraction cerebral angiography (postoperative - following carotid ligation) showing a patent high-flow saphenous vein graft from the cervical external carotid artery to middle cerebral artery and total occlusion of the cervical carotid artery

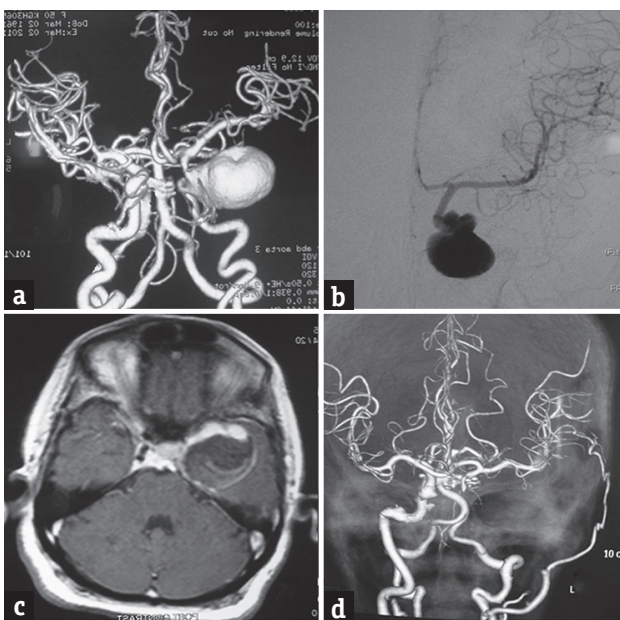

Figure 3: ( $a$ and b) Computed tomography angiogram and (a) 4-vessel digital subtraction cerebral angiography, (b) a giant cavernous aneurysm on the left side. (c) Magnetic resonance imaging brain T1-weighted contrast sequence suggestive of intramural thrombus, (d) postoperative computed tomography angiogram showing nonfilling of the aneurysm and a patent superficial temporal to middle cerebral anastomosis

BTO was performed initially for $15 \mathrm{~min}$ at normal blood pressure and those patients who tolerated BTO were subjected to hypotensive challenge. The balloon was deflated if the patient tolerated ICA occlusion after hypotensive challenge or developed a gross neurological deficit during 20-min of parent vessel occlusion. Low-flow augmentative bypass (ST-MC) was used in patients with good cross-circulation who tolerated balloon occlusion with hypotensive challenge [Figure 3]. High-flow bypass (using saphenous vein graft) was done in patients with poor cross-circulation and those who did not tolerate BTO [Figure 4]. In the subsequent period, BTO could not be done due to technical reasons, and a high-flow EC-IC bypass with parent artery occlusion

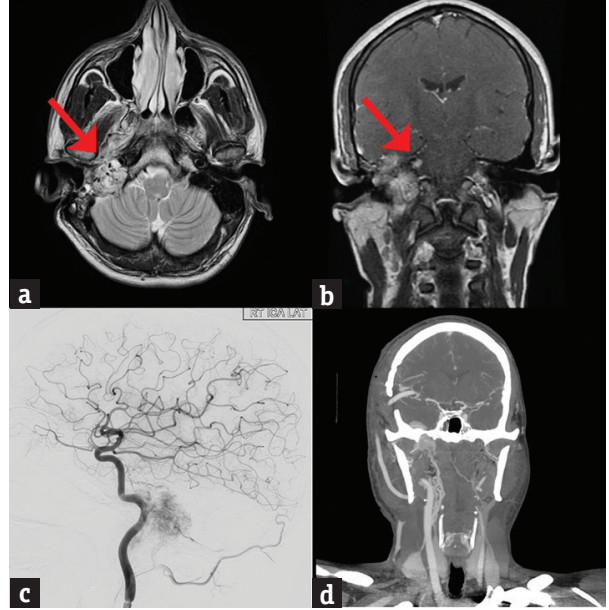

Figure 2: ( $a$ and b) MRI images axial T2 (a), post contrast coronal (b) showing an extensive skull base glomus jugulare encasing the carotid artery. The red arrows point to the tumour within the petrous encasing the carotid, (c) preoperative digital subtraction cerebral angiography showing the tumor blush surrounding the cervical and petrous carotid artery, (d) computed tomography angiogram (postoperative) showing a patent high-flow saphenous vein graft from the cervical external carotid artery to middle cerebral artery

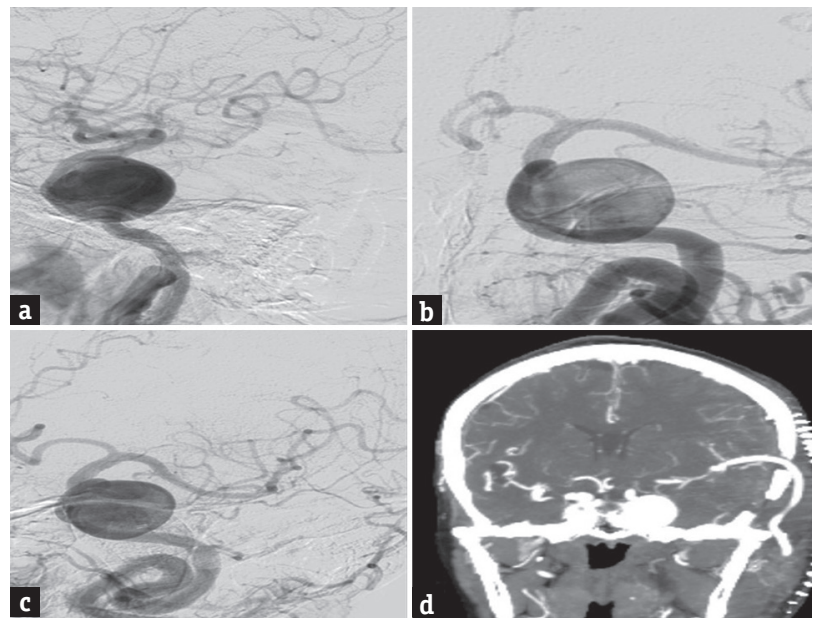

Figure 4: (a-c) Left internal carotid artery digital subtraction cerebral angiography-lateral (a), anteroposterior (b) and oblique (c) images showing a giant left cavernous carotid artery aneurysm, (d) computed tomography angiogram (postoperative - before carotid ligation) showing a patent high-flow saphenous vein graft from the cervical external carotid artery to middle cerebral artery

was done in all the patients, irrespective of the status of the CVR. The aneurysm was thereafter excluded from circulation by parent vessel (ICA) ligation alone, and none of the patients underwent trapping of the aneurismal segment. Single-photon emission computed tomography (SPECT), positron emission tomography (PET), perfusion studies, and/or other cerebral blood flow/CVR studies were not done in any of our patients.

\section{RESULTS}

Twelve patients who tolerated the BTO well underwent low-flow augmentative bypass using an end-to-side 
superficial temporal artery to middle cerebral artery (STA-MCA) bypass. Four patients who failed the BTO and seven patients in whom BTO could not be done underwent a direct high-flow bypass using a saphenous vein graft. All patients underwent permanent ICA occlusion as a second-stage procedure. We had two mortalities and a poor outcome in one patient. One patient who underwent STMC bypass for a giant cavernous IC aneurysm rapidly deteriorated and succumbed to an acute subdural hematoma probably due to a leak from the anastomotic site. One patient with a high-flow bypass developed a massive IC infarct secondary to shunt occlusion and succumbed. Another patient who underwent high-flow bypass developed a contralateral ICA infarct with associated deficits and was discharged in a vegetative state. All other patients had a good recovery and were in good neurological grade with a Glasgow outcome score of 5 at the last follow-up. Recovery of ocular cranial nerve palsies was however incomplete, with only seven patients showing complete recovery. Graft patency was observed on check angiograms (DSA or CTA) in nine of the eleven surviving patients following STMC bypass [Figure 3]. Both these patients were operated in the initial part of the series. In these two patients, parent ligation was nevertheless carried out in spite of an absent flow through the graft as the patients were found to have good collaterals and adequate CVR on balloon occlusion studies. Graft patency was observed in all the nine high-flow bypass patients who had good outcome [Figure 4]. Chest angiogram revealed thrombosis of the aneurysm in all the patients where parent artery ligation was carried out. The patient with glomus jugulare underwent tumor excision with carotid artery sacrifice and had a good outcome.

\section{Discussion}

EC-IC bypass technique was first used in the treatment of ischemic stroke, and the first intracranial EC-IC bypass surgery was performed by Donaghy and Yasargil in 1967. ${ }^{[12]} \mathrm{EC}-\mathrm{IC}$ bypass for ischemic stroke prevention has not stood the test of time, and repeated trials have failed to prove its efficacy in revascularization for ischemic stroke. ${ }^{[14]}$ However, bypass surgery is being increasingly considered as an effective supplementary modality in the management of complex intracranial aneurysms and difficult skull base lesions where the parent artery sacrifice needs to be sacrificed. Recent clinical publications and current evidence suggest a revival of EC-IC bypass surgery, especially in the management of unclippable complex aneurysms and cranial base tumors involving major cranial arteries..$^{[1,6,11,15-18]}$

\section{Indications for bypass procedure}

CCAs represent approximately $3 \%-5 \%$ of all intracranial aneurysms and $15 \%$ of those arising in the ICA. ${ }^{[19,20]}$ The natural history of these aneurysms is not well known. ${ }^{[20,21]}$ Quite often, they are detected incidentally. When symptomatic, they present with symptoms related to their large size, intramural thrombus, and subsequent neurovascular compression. Thus, diplopia and ophthalmoparesis are the most common presenting features coupled with retro-orbital pain, headache, or facial pain. Presentation with bleed is uncommon and may occur in two instances. Subarachnoid hemorrhage can occur from the intradural component of a transitional variant of cavernous aneurysms. Epistaxis can result when a long-standing giant aneurysm erodes the wall of the sphenoid sinus and bleeds. The management dilemma essentially is in deciding whether an asymptomatic aneurysm will turn symptomatic and whether the risks of treatment are less than the risks of the natural history of the disease. The current evidence suggests that asymptomatic aneurysms are better treated if they have an intradural component or if imaging reveals erosion of the lateral wall of the sphenoid sinus indicating a potential for fatal epistaxis. ${ }^{[20,21]} \mathrm{Few}$ cases of spontaneous thrombosis of cavernous carotid aneurysms have been reported. However, symptomatic giant aneurysms too are best treated as they definitely carry a risk of lifethreatening hemorrhage, thromboembolism, and worsening cranial nerve palsies. ${ }^{[22]}$ All the cavernous aneurysm patients in this series were symptomatic. Surgery was preferred over interventional procedures due to financial constraints. Another indication for bypass arises in patients with large skull base lesions engulfing the carotid artery where radical resection mandates carotid ligation. One of our patients had a large recurrent glomus jugulare extending into the neck and encasing the carotid artery. A bypass procedure was planned for him before radical excision of the tumor.

\section{Selection of treatment procedure}

Isolation of the aneurysm can be done either surgically or through interventional neuroradioloigcal means. High cost of treatment and risks associated with prolonged anticoagulants negate the obvious benefits of interventional techniques, especially in developing countries like India. Surgical treatment can be either by direct clipping of the aneurysm or indirectly by parent artery ligation coupled with a bypass procedure. Direct surgical clipping of giant unruptured cavernous aneurysms carries a high rate of mortality and morbidity which can be as high as $4 \%$ and $19 \%$, respectively, and has been practically abandoned even by accomplished cerebrovascular surgeons. ${ }^{[20,21,23,24]}$ Parent artery ligation 
with or without an augmentative bypass procedure has helped reduce the mortality and morbidity rates to as low as $0 \%$ and $20 \%$, respectively, in few series. ${ }^{[25-28]}$

\section{Preoperative assessment}

CCAs were historically treated by parent artery occlusion by direct carotid ligation. ${ }^{[25,26]}$ These procedures carry a risk of morbidity and mortality between $10 \%$ and $20 \%$ and a potential for contralateral aneurysm development. ${ }^{[1,25,26,29]}$ It is, therefore, important to evaluate the risk of infarction from carotid occlusion before permanent ICA sacrifice. Decision regarding the need for bypass essentially depends on the adequacy of collateral cerebral circulation and the contralateral hemisphere to support the vascular demand of the ipsilateral hemisphere. This is done by assessing the CVR of the patient. ${ }^{[10,30]}$

Many techniques have been developed to evaluate CVR. ${ }^{[21,31]}$ The first attempt toward this was made by Matas in 1911 through manual carotid compression which proved to be inadequate. ${ }^{[21]}$ Cross-compression angiography and the presence of good collaterals on angiography are good predictors, but again not a reliable tool as they do not simulate a real-time ICA occlusion scenario. The introduction of BTO has reduced the risk of stroke and death after carotid ligation which used to be approximately $25 \%$ and $12 \%$, respectively. ${ }^{[32]}$ However, a significant percentage of patients with acceptable BTO results still develop infarction. Other techniques used in combination with BTO include quantitative CBF analysis using SPECT, ocular plethysmography, somatosensory-evoked potentials, xenon-enhanced CT, and PET. The addition of physiologic stressors (e.g., induced hypotension and acetazolamide injection) aids in the identification of patients with compromised CVRs. Recently, CT and MR perfusion techniques are also increasingly being used to assess CVR. Elhammady et al. advocated monitoring the carotid stump pressure before carotid occlusion to decide the treatment strategy. ${ }^{[2]}$ If the mean stump pressure decreases by $30 \%-70 \%$ of the mean preclamping pressure and electroencephalograms do not change during the 15 min of temporary CCA occlusion, the patient is presumed to be a good candidate for permanent ICA occlusion. If stump pressure decreases by more than $70 \%$ with CCA occlusion, the risk of ischemia is high, and the patient should be considered for an extracranial-intracranial bypass before trapping. Moreover, if the pressure does not decrease by more than $30 \%$, the chance of aneurysm thrombosis is low and the aneurysm needs to be trapped either surgically or endovascularly.
Uncertainty of balloon test occlusion and the need for bypass in patients with good cross-circulation and collateral reserve

However, it is well documented that none of these tests are foolproof and 5\%-10\% of patients with good cross-circulation carry a risk of ischemia after carotid occlusion. Previous series have reported a stroke rate of $10 \%-12 \%$ after permanent ICA occlusion based on clinically tolerated BTO and $32 \%-60 \%$ risk of complications associated with carotid ligation done without any preoperative assessment. ${ }^{[21,33]}$ Passing BTO with flow studies does not rule out the chance of infarction which can still be as high as $20 \%-22 \%$ rate of infarction. ${ }^{[21]}$ SPECT, PET, xenon-enhanced CT, stump pressure measurements, and MR perfusion studies can further reduce the risk of ischemic complications from $13 \%$ to $10 \%$, but have inherent drawbacks especially in watershed areas. Segal et al. after analyzing their series and those in published literature concluded that failure of BTO can identify those patients at increased risk for stroke after carotid ligation. ${ }^{[30,33]}$ However, a normal BTO and cerebral blood flow studies did not indicate that carotid ligation can be performed safely. Prophylactic revascularization surgeries help prevent the uncertainties of ischemic complications in spite of a positive BTO.

\section{Choice of bypass}

Conventional teaching recommends extracranial-intracranial bypass if there is evidence of insufficient cerebral reserve and carotid ligation if there is evidence of adequate cerebral collateral flow. Defining "adequacy of collateral flow" is controversial. Kuroda et al. have evolved a treatment strategy of bypass selection based on BTO and SPECT. ${ }^{[27]}$ Patients with BTO evidence of profound ischemia undergo a high-flow venous bypass graft before ICA sacrifice. Patients without ischemic symptoms during BTO, but having at-rest SPECT evidence of hypoperfusion in the ipsilateral hemisphere, undergo a medium-flow bypass. Patients without ischemic symptoms during BTO, normal at-rest SPECT results, but having hypo-vasoreactivity of the ipsilateral hemisphere under acetazolamide stress, undergo low-flow (STA-MCA) bypass. Only patients who tolerate BTO and manifest no hypoperfusion on at-rest and acetazolamide-stressed SPECT study during ICA occlusion were considered candidates for direct ICA occlusion by Kuratsu. ${ }^{[27]}$ Available literature is divided on this issue. These tests are not feasible due to infrastructure constraints in many centers. Moreover, in spite of all positive evidence, carotid artery ligation always carries a risk of ischemic complications. Several authors, therefore, recommend revascularization high-flow bypass procedures for all patients (the universal approach). ${ }^{[1,6,15]}$ 
Infrastructure and technical limitations prevented us from doing detailed CVR studies in all patients. BTO could be done only in the first 12 patients, and other cerebral blood flow studies could not be done in any patient. In the initial part of our series, we adopted a policy of doing a low-flow STMC bypass for patients who could tolerate BTO and a high-flow bypass in those who could not. Subsequently, we switched to a universal high-flow bypass procedure for all patients due to technical difficulties in performing a BTO. Our complication rate and surgical outcome are comparable with published literature. Our data suggest that universal high-flow bypass using a saphenous vein graft before carotid artery ligation is a safe and effective treatment option, especially in centers ill-equipped to perform comprehensive CVR studies.

\section{Complications and their avoidance}

Cerebral anastomosis techniques have a sharp learning curve and training with practice in microvascular skill laboratories is mandatory. Major complications associated with STA-MCA bypasses include graft occlusion, subgaleal hematoma, scalp necrosis, and postoperative intracranial hemorrhage. Meticulous dissection, minimal handling of the endothelium, adequate hemostasis, limited cortical dissection, and preservation of veins are important steps. ${ }^{[8]}$ Pre- and postoperative use of antiplatelet agents and anticoagulants may help reduce thrombosis-related problems. Intraoperative use of heparin is limited to high-flow anastomosis as a single dose of 5000 units of heparin is administered intravenously. Brain protection provided using propofol or pentobarbital helps protect the brain during temporary arterial occlusion for bypass. Attempts to reduce clamp time at the expense of a meticulous anastomosis are to be avoided. Graft occlusion is another common complication with patency rates reported from $66 \%$ to $95 \%$. Most of the causes of graft occlusion are technical and majority of them can be avoided by practicing meticulous techniques. Our complications were predominantly due to surgical inadequacies in cerebrovascular anastomosis techniques. With experience and refinement, the complications have also reduced.

\section{Conclusion}

Carotid artery ligation carries a potential risk of ischemic complications even in patients with good collaterals and adequate cross-circulation. BTO and CVR studies are technically complex and not feasible in all patients. Universal high-flow bypass is a safe and effective alternative in all such patients and obviates the need for detailed CVR assessment.

\section{Financial support and sponsorship}

Nil.

\section{Conflicts of interest}

There are no conflicts of interest.

\section{REFERENCES}

1. Sekhar LN, Bucur SD, Bank WO, Wright DC. Venous and arterial bypass grafts for difficult tumors, aneurysms, and occlusive vascular lesions: Evolution of surgical treatment and improved graft results Neurosurgery 1999;44:1207-23.

2. Elhammady MS, Wolfe SQ, Farhat H, Ali Aziz-Sultan M, Heros RC. Carotid artery sacrifice for unclippable and uncoilable aneurysms: Endovascular occlusion vs. common carotid artery ligation. Neurosurgery 2010;67:1431-6.

3. Gelber BR, Sundt TM Jr. Treatment of intracavernous and giant carotid aneurysms by combined internal carotid ligation and extra- to intracranial bypass. J Neurosurg 1980;52:1-10.

4. Odom GL, Tindall GT. Carotid ligation in the treatment of certain intracranial aneurysms. Clin Neurosurg 1968;15:101-16.

5. Giannotta SL, McGillicuddy JE, Kindt GW. Gradual carotid artery occlusion in the treatment of inaccessible internal carotid artery aneurysms. Neurosurgery 1979;5:417-21.

6. Sekhar LN, Patel SJ. Permanent occlusion of the internal carotid artery during skull-base and vascular surgery: Is it really safe? Am J Otol 1993;14:421-2.

7. Park EK, Ahn JS, Kwon DH, Kwun BD. Result of extracranial-intracranial bypass surgery in the treatment of complex intracranial aneurysms: Outcomes in 15 cases. J Korean Neurosurg Soc 2008;44:228-33.

8. Sanuş GZ, Akar Z, Tanriverdi T, Tütüncüler B, Uzan M, Işlak C, et al. Bypass to the intracranial giant or large internal carotid artery aneurysms: Superficial temporal artery to middle cerebral artery bypass re-visited. Turk Neurosurg 2007;17:60-5.

9. Erba SM, Horton JA, Latchaw RE, Yonas H, Sekhar L, Schramm V, et al. Balloon test occlusion of the internal carotid artery with stable xenon/CT cerebral blood flow imaging. AJNR Am J Neuroradiol 1988;9:533-8.

10. Sudhakar KV, Sawlani V, Phadke RV, Kumar S, Ahmed S, Gujral RB. Temporary balloon occlusion of internal carotid artery: A simple and reliable clinical test. Neurol India 2000;48:140-3.

11. Jafar JJ, Russell SM, Woo HH. Treatment of giant intracranial aneurysms with saphenous vein extracranial-to-intracranial bypass grafting: Indications, operative technique, and results in 29 patients. Neurosurgery 2002;51:138-44.

12. Donaghy RM, Yasargil G. Microangeional surgery and its techniques. Prog Brain Res 1968;30:263-7.

13. Menon G, Jayanand S, Krishnakumar K, Nair S. EC-IC bypass for cavernous carotid aneurysms: An initial experience with twelve patients. Asian J Neurosurg 2014;9:82-8.

14. EC/IC Bypass Study Group. Failure of extracranial-intracranial arterial bypass to reduce the risk of ischemic stroke. Results of an international randomized trial. N Engl J Med 1985;313:1191-200.

15. Sekhar LN, Duff JM, Kalavakonda C, Olding M. Cerebral revascularization using radial artery grafts for the treatment of complex intracranial aneurysms: Techniques and outcomes for 17 patients. Neurosurgery 2001;49:646-58.

16. Sundt TM Jr., Piepgras DG, Marsh WR, Fode NC. Saphenous vein bypass grafts for giant aneurysms and intracranial occlusive disease. J Neurosurg 1986;65:439-50.

17. Reynolds MR, Derdeyn CP, Grubb RL Jr., Powers WJ, Zipfel GJ. 
Extracranial-intracranial bypass for ischemic cerebrovascular disease: What have we learned from the carotid occlusion surgery study? Neurosurg Focus 2014;36:E9.

18. Kubo Y, Ogasawara K, Tomitsuka N, Otawara Y, Kakino S, Ogawa $\mathrm{A}$, et al. Revascularization and parent artery occlusion for giant internal carotid artery aneurysms in the intracavernous portion using intraoperative monitoring of cerebral hemodynamics. Neurosurgery 2006;58:43-50.

19. Penchet G, Mourier K. Collaborative retrospective multicentre series of giant intracavernous carotid aneurysms. Neurochirurgie 2015;61:366-70.

20. Stiebel-Kalish H, Kalish Y, Bar-On RH, Setton A, Niimi Y, Berenstein A, et al. Presentation, natural history, and management of carotid cavernous aneurysms. Neurosurgery 2005;57:850-7.

21. Ambekar S, Madhugiri V, Sharma M, Cuellar H, Nanda A. Evolution of management strategies for cavernous carotid aneurysms: A review. World Neurosurg 2014;82:1077-85.

22. Vasconcellos LP, Flores JA, Conti ML, Veiga JC, Lancellotti CL. Spontaneous thrombosis of internal carotid artery: A natural history of giant carotid cavernous aneurysms. Arq Neuropsiquiatr 2009;67:278-83

23. Date I, Ohmoto T. Long-term outcome of surgical treatment of intracavernous giant aneurysms. Neurol Med Chir (Tokyo) 1998;38Suppl:62-9.

24. Barnett DW, Barrow DL, Joseph GJ. Combined extracranial-intracranial bypass and intraoperative balloon occlusion for the treatment of intracavernous and proximal carotid artery aneurysms. Neurosurgery 1994;35:92-7.

25. Drake CG, Peerless SJ, Ferguson GG. Hunterian proximal arterial occlusion for giant aneurysms of the carotid circulation.
J Neurosurg 1994;81:656-65.

26. Voris HC. Complications of ligation of the internal carotid artery. J Neurosurg 1951;8:119-31.

27. Kai Y, Hamada J, Morioka M, Yano S, Mizuno T, Kuroda J, et al. Treatment strategy for giant aneurysms in the cavernous portion of the internal carotid artery. Surg Neurol 2007;67:148-55

28. Zhu W, Tian YL, Zhou LF, Song DL, Xu B, Mao Y, et al. Treatment strategies for complex internal carotid artery (ICA) aneurysms: Direct ICA sacrifice or combined with extracranial-to-intracranial bypass. World Neurosurg 2011;75:476-84.

29. Diaz FG, Ausman JI, Pearce JE. Ischemic complications after combined internal carotid artery occlusion and extracranial-intracranial anastomosis. Neurosurgery 1982;10:563-70.

30. Segal DH, Sen C, Bederson JB, Catalano P, Sacher M, Stollman AL, et al. Predictive value of balloon test occlusion of the internal carotid artery. Skull Base Surg 1995;5:97-107.

31. Yamashita T, Kashiwagi S, Nakano S, Takasago T, Abiko S, Shiroyama Y, et al. The effect of EC-IC bypass surgery on resting cerebral blood flow and cerebrovascular reserve capacity studied with stable XE-CT and acetazolamide test. Neuroradiology 1991;33:217-22.

32. Tanaka F, Nishizawa S, Yonekura $\mathrm{Y}$, Sadato N, Ishizu K, Okazawa $\mathrm{H}$, et al. Changes in cerebral blood flow induced by balloon test occlusion of the internal carotid artery under hypotension. Eur J Nucl Med 1995;22:1268-73.

33. Sorteberg A, Bakke SJ, Boysen M, Sorteberg W. Angiographic balloon test occlusion and therapeutic sacrifice of major arteries to the brain. Neurosurgery 2008;63:651-60. 